\title{
HOW IMPORTANT IS THE TRANSPORT INCUBATOR? HYPOTHERMIA RATES IN PREMATURE NEONATES AFTER INCUBATOR MALFUNCTION.
}

Andrews C, Lee R, Qayum A

Background: In neonates, hypothermia (temperature $<36.5^{\circ} \mathrm{C}$ ) causes significant morbidity and mortality, particularly in premature and low birth weight infants. Research has shown a statistically significant increase in mortality risk with admission hypothermia, alongside complications of respiratory distress, increased sepsis risk and a higher incidence of intraventricular haemorrhage.

Adequate thermoregulation is an important factor in the resuscitation and stabilisation of the most at risk new-born babies on transfer and admission to NICU

Aims: To assess the impact of transport incubator break-down on admission temperatures for infants $\leq 32+6$ weeks gestation in a level 2 NICU.

Methods: Retrospective analysis of admission temperatures over 4 months when the transport incubator was unavailable and alternative transport on an open resuscitare was practiced. Comparison to the prior 4 month period, and the same 4 month period the year before.
Axilla temperature measured with digital thermometer on admission to NICU.

Hypothermia was considered a temperature $<36.5^{\circ} \mathrm{C}$.

Results: There were 14 admissions, without the transport incubator. Similar rates of admission in the other time frames studied. Gestational age ranged from $24+4$ to $32+5$ weeks. $100 \%$ of infants $\leq 29+6$ were hypothermic. Compared to the preceding 4 months, the increase in hypothermia was statistically significant, $p=0.033^{*}$.

Results: Rates of hypothermia matched with gestation.

\begin{tabular}{|l|l|l|l|l|l|l|}
\hline \multicolumn{2}{|l|}{} & \multicolumn{2}{l|}{ Without incubator (N=14) } & \multicolumn{2}{l}{$\begin{array}{l}\text { With incubator 4 moths prior } \\
(\mathrm{N}=22)\end{array}$} & \multicolumn{2}{l}{$\begin{array}{l}\text { With incubator previous year } \\
(\mathrm{N}=14)\end{array}$} \\
\hline Gestation & $\begin{array}{l}\text { temp }<36.5 \\
\mathrm{n}(\%)\end{array}$ & $\begin{array}{l}\text { temp }>36.5 \\
\mathrm{n}(\%)\end{array}$ & $\begin{array}{l}\text { temp <36.5 } \\
\mathrm{n}(\%)\end{array}$ & $\begin{array}{l}\text { temp }>36.5 \\
\mathrm{n}(\%)\end{array}$ & $\begin{array}{l}\text { temp <36.5 } \\
\mathrm{n}(\%)\end{array}$ & $\begin{array}{l}\text { temp }>36.5 \\
\mathrm{n}(\%)\end{array}$ \\
\hline$<28$ weeks & $2(100)$ & 0 & 0 & $2(100)$ & $2(100)$ & 0 \\
\hline $28-29+6$ & $4(100)$ & 0 & $2(29)$ & $5(71)$ & $3(75)$ & $1(25)$ \\
\hline $30-32+6$ & $3(37)$ & $5(63)$ & $3(23)$ & $10(77)$ & $3(37)$ & $5(63)$ \\
\hline Total & $\mathbf{9 ( 6 4 )}$ & $\mathbf{5 ( 3 6 )}$ & $\mathbf{5 ( 2 3 )}$ & $\mathbf{1 7 ( 7 7 )}$ & $\mathbf{8 ( 5 7 )}$ & $\mathbf{6 ( 4 3 )}$ \\
\hline
\end{tabular}

Conclusions: Comparing two adjacent time frames of admission temperatures to NICU with and without the transport incubator demonstrated significant increase in hypothermia during the equipment break-down. Our findings demonstrate the deleterious effect of this and the importance of having effective contingency plans to prevent harm to our most vulnerable patients.

The overall rates of hypothermia on admission are noted to be unexpectedly high, particularly in the two time periods studied over corresponding winter months leading to review of the thermoregulation policy and implementation of new guidance. Continued audit and service evaluation are valuable opportunities to reduce risk and improve patient care. 